Article

\title{
Optimization of Container Terminal Layouts in the Seaport-Case of Port of Montreal
}

\author{
Tareq Abu Aisha *, Mustapha Ouhimmou and Marc Paquet \\ Department of Systems Engineering, École de Technologie Supérieure, 1100 Rue Notre-Dame Ouest, Montreal, \\ QC H3C 1K3, Canada; Mustapha.Ouhimmou@etsmtl.ca (M.O.); Marc.Paquet@etsmtl.ca (M.P.) \\ * Correspondence: Tareq-ali-issa.abu-aisha.1@ens.etsmtl.ca
}

Received: 17 December 2019; Accepted: 4 February 2020; Published: 6 February 2020

\begin{abstract}
The intermodal transportation system plays a pivotal role in a global supply chain. Despite the benefits of intermodal transportation, it still has negative impacts, which are associated with congestion and emission. Greenhouse Gas (GHG) emission is highly associated with the transportation industry, and the share of the transportation sector is growing at a rapid pace. This paper discusses intermodal transportation and its effects on port efficiency. We proposed a new layout for the container terminal in the seaport in order to decrease cost as well as emission generated by the port operations. The proposed layout can improve the sustainability of port activities by decreasing the distance between the berth and interface points as well as avoiding double handling. We propose multi-objective optimization using the $\varepsilon$-constraint method to solve this problem. The model was tested through a case study of the Port of Montreal in Canada. The findings reveal that the proposed layout resulted in considerable emissions and costs reduction. Compared with the current layout of Port of Montreal, the proposed layout achieved a reduction of $46.5 \%$ in the total transportation cost of the containers to their final destination, as well as $21.6 \%$ in the emission.
\end{abstract}

Keywords: maritime transportation; intermodal transportation; container terminals; sustainable terminals

\section{Introduction}

It is worth noting that the massive amount of global trade flows between the countries through seaports. These seaports, in the past, acted as a point to change the mode of transportation only. However, currently, the ports exceeded this traditional concept and became logistic centers and intermodal terminals. The intermodal transportation term indicates to transport the cargo from origin-destination to final destination in the same loading unit without handling merchandise themselves during the exchange between transportation modes [1]. As a result of the increase in the size of container ships, advantages of economy of scale, and global competition, the ports are suffering from a lot of obstacles and challenges limiting their ability to survive and grow. The increase in the size of ships causes congestion in the ports and the area surrounding the port, and usually slows down the flow of containers. The studies show that about $65 \%$ of delay in maritime transportation is because of congestion in the ports [2].

In most cases, long distances separate the source of raw material (production site) from the consumption location, and usually, these locations are separated by oceans. Therefore, transportation, especially maritime transportation and the container terminal, is considered as the most significant component of the cost structure of the global supply chain [3]. Consequently, seaports have been enforced to meet the increased needs of global supply chains and flow of commodities. In order to meet the increased demands, intermodal transportation is being used. The use of efficient intermodal transportation has significantly reduced handling operations and congestion at ports and all other 
transfer points, thus increasing the efficiency of the ports [4]. Intermodal transportation is also playing a significant role in the industry of freight transportation because of its benefits regarding minimization of cost, greenhouse gas emissions (GHG), and congestion [5]. Trans-shipment operations in intermodal transportation systems in the container terminal also releases GHG emissions. The emissions from these operations in a particular terminal depend on the type of equipment used for handling the containers and infrastructure and layout of the terminal [5]. However, greenhouse gas emission is a significant threat to the human and environment [3].

Globally, in 2016, the transportation sector represents one-quarter of overall emissions at about $8 \mathrm{GtCO} 2$, which is a level $71 \%$ higher than what it was in the year of 1990 . Road transportation constituted the highest percentage. Overall, the share of air and water transport remained unchanged while road transport emissions increased by two percentage points to $74 \%$ [6].

In Canada, approximately 20\% (by dollar value) of Canadian imports and exports are transported by maritime transportation. Canadian ports are in need of a move forward in environmental performance, concurrently, to meet the sustainability demands [7]. Though, as our research is concentrated upon reduction of GHG and cost at Canadian Ports, it has been seen that in 2017, the total greenhouse gas (GHG) emissions in Canada reached 716 megatons of carbon dioxide equivalent or $\mathrm{CO}_{2}$ eq; the second-largest GHG emitter in Canada was the transportation sector with $174 \mathrm{MtCO}_{2}$ eq, meaning $24 \%$ of total emissions, closely followed by the largest emitter in Canada, the oil and gas sector that emitted $195 \mathrm{Mt} \mathrm{CO}_{2}$ eq, and representing 27\% of total emissions. The increase in GHG emissions was mostly due to growth in the transportation and oil-gas sectors. Regarding transportation emissions, from 1990 to 2017, GHG emissions from the transportation sector increased by 43\%. This increase was due to freight trucks, whereas it increased by 122\% between 1990 and 2017 [8]. The amount of transportation emissions depends on the amount of fuel used [5]. Generally, fuel consumption can be calculated by taking into account many factors such as road type, loading factors, and speed. So, we assume the value of 3.24 kilograms $\mathrm{CO}_{2}$ emissions per ton as the emissions factor used for diesel [5]. The energy consumption of the equipment that is used in handling containers relies on the traveled distances between the different sub-processes. However, the consumption of energy can be calculated, taking into account these distances by type of equipment, per modality [9]. In order to overcome these challenges, seaports need particular attention to deliver their service to their stakeholders in an efficient and productive way [10].

The transportation sector represents $30 \%$ of the overall cost of logistics operations [11]. The growth in demand for container transport has many undesirable effects (congestion, emissions, noise, etc.). Unfortunately, it generates a conflict with the port city as it has to endure the undesirable effects of the port operations. In this regard, sustainable solutions are essential for the development of both ports and surrounding urban areas [12]. One major tradeoff between the transportation systems is its effect on the environment. Thus, calculating the emissions from all transportation systems is the main step in the performance measurement for the transportation system [13].

The minimization of transportation costs is the key objective of traditional logistics models. However, taking into account wider objectives and problems such as changes in the layout of container terminals, reduction of GHG emissions, and a decrease of congestion will lead to new models and solutions. These models and solutions can be used to define efficient intermodal transportation [3]. In this paper, the above-defined intermodal problems have been considered. In the case of the container terminals, in which every container terminal has a particular design and layout with distinctive dimensions between interface points, we use the concept of the dry port as one of the ways to increase the use of rail transportation instead of trucks [4]. The current study uses the concept of the dry port by introducing a new container terminal far from the seaport in the proposed layout model. Thus, the result of solving such problems and overcoming the challenges will be the increase in terminal productivity. Moreover, it will minimize transportation time, cost, and emissions (sustainability), followed by an increase in the capability of the container terminal to meet the recent high demand for containerization. However, this paper makes a comparison between the common layouts of the 
container terminal with a new proposed developed layout. This comparison is in terms of cost and emission generated by different equipment and modes of transportation used in transferring containers from the container ship to their final destination. The multi-objective optimization approach has been used to optimize the model. In this paper, we took the case of Port of Montreal to validate the proposed model.

The remainder of the paper is organized as follows: In Section 2, a comprehensive review of previous researches relevant to the current study will be discussed. Section 3 presents a real case study. Sections 4 and 5 are devoted to the problem definition and problem formulation. Section 6 analyzes computational results. The conclusion is reported in Section 7.

\section{Literature Review}

The basic concept of intermodal transportation is consolidating shipments for efficient long-distance transportation such as by large ocean vessels or rail, at the same time, taking advantage of the efficiency of local delivery and truck pick-up operations. The definition of Intermodal Transportation is transporting cargo from origin to its final destination in the same transportation unit [14]. The cargo itself is not handled during the transferring activity from one mode of transportation to another [2]. Due to the advantages of trucking transportation, such as flexibility and high frequency, the market share of trucking transportation is increasing around the world [15]. All these have caused huge truck flows and congestion on public roads and in cities. In addition to that, it produces a high level of emissions. In Canada, based on The Railway Association of Canada, 2006, the number of intermodal carloads increased by $77.5 \%$ in the last decade; this demonstrates $26.3 \%$ of the overall growth in carloads industry appearing during this period. Avoiding congestion and unplanned delays are one of the primary objects in intermodal terminals' operations. Intermodal transportation performance is associated with the performance of every component of the chain individually, ports, maritime lines companies, motor carriers and rail, also the efficient integration between them regarding operations, decisions, and information [16]. In this respect, the authors in [16] provided an overview of the intermodal transportation system. This study presented intermodal transportation from the perspective of both carriers and suppliers; as well, the study showed significant problems and difficulties in planning, designing, and operating networks of intermodal transportation. The study focused on the modeling approach, and it paid attention to the role of operations research in the intermodal transportation domain [16]. Most studies in the field of intermodal transportation have only focused on minimizing operation costs as a single objective $[15,17,18]$. For ensuring the intermodal transportation system efficiency, some researches on the intermodal transportation system are focused on analyzing the optimal location of the intermodal terminal itself $[17,18]$. The European Commission has pointed out that it is necessary to use efficient intermodal transport instead of using unimodal road transport, in light of the evidence that the latter contributes significantly to increasing $\mathrm{CO}_{2}$ emissions [17].

The container's flow from port to the next destination has become a challenge for many container terminals in the ports. Although using trucks offers door-to-door service that cannot be provided by the train service, using this option is impeded due to congestion and emissions. The use of trains has the advantage of preventing congestion, thus decreasing container delivery time resulting in minimizing transport cost and accelerating containers' flow [18]. European Commission aims to shift $30 \%$ of transported freight more than $300 \mathrm{~km}$ by trucks to rail or maritime transportation by 2030 , with more than $50 \%$ by 2050 [19]. A comprehensive study by P.T. Aditjandra et al. in 2016, investigated the advantages of rail transportation to enhance sustainable transportation [20]. A large number of existing studies in the broader literature have investigated the economic and environmental benefits of shifting freight transport from road to rail transportation [21-25]. Regarding all these concerns, Woodburn [21] investigated the effect of rail track transportation on container flow and port efficiency in the United Kingdom by using a 'before and after' survey of the capacity of container train supply and loading factors. The author found that rail connectivity is essential for efficient container flow, which means better port efficiency [21]. Similarly, the author in [22] investigated the relationship between 
the operating environment and port efficiency. The study took 420 container terminals as a sample to study the operating conditions and the market. The terminal efficiency is significantly influenced by operating conditions changes [22]. Another study shows how the amount of equipment on the site has an impact on delay more than it does on the throughput time of the train [23]. Providing a sufficient and integrated rail network and excellent organization for train schedules to meet the demand helps containers in traffic processes and minimizes transport costs. In addition, it enables shipping companies to offer reliable services at a competitive cost. However, developed network designs by using real-world data guarantee the applicable plans that assist decision-makers in utilizing advantages of distribution network designs. Such researches seek to improve port operations' efficiency. Due to increased pressure on industries and governments to come forward with initiatives to reduce GHG emissions, the reduction of GHG emissions has become a priority for these organizations [24]. Chen et al. used Interpretative Structural Modeling (ISM) to analyze relationships between different structural factors, and they propose governance policies and specific countermeasures to construct green and smart ports [25]. Gibbs et al. conducted a study to evaluate the role of seaports in the chain of maritime transport emissions. Port operations and transportation activities from the port to hinterland generate a large amount of emissions [26].

Some publications have appeared in recent years documenting the assessment of the current state of sustainability in Canadian ports by analyzing their strategy and KPIs to meet sustainability goals such as $[7,27]$. Although some research has been carried out on sustainability in Canadian ports, to our knowledge, no single study exists, which adequately covers the effect of changing the layout of the container terminal in the port on the transportation cost and emission.

It is not easy to make a comprehensive estimation of the total emissions generated in the seaport [27]. Although there is intensive research to calculate the environmental performance for modes of transportation, most of them investigate the negative effect on the environment for each mode of transportation individually. Some of these studies investigated the emissions generated from shore crane [28]. Liu et al. studied the emissions from gantry crane in the terminal [29]. The emissions from yard tractor in the terminal have been investigated by Yu, Ge, Chen et al. [30], while the emissions from the trucks were investigated by Berechman and Tseng [31]. Since the terminal operators do not own these trucks, thus terminal operators do not have direct control over reducing emissions from these trucks. In some ports with fewer environmental regulations, the trucks are responsible for generating a significant share of emissions in the port. Therefore, optimizing truck flow to reduce idling time for trucks in the terminal is the only action terminal operators can take to reduce the emissions [32].

There are different models to calculate fuel consumption and emissions from freight transportation. Demir et al. conducted a study to compare some models that have been deployed to calculate greenhouse gas emissions and fuel consumption related to road freight transportation. The results of this study showed there are some differences in findings in simulations of the models using largely realistic assumptions, but in general, are consistent with their expectations, such as consumption of fuel differs with the size of the vehicle, road track gradient, and speed [33]. For policymakers, and as a first step, it is essential to understand the quantity of $\mathrm{CO}_{2}$ emissions for different terminals [9]. Some studies focus on analyzing and estimating emissions from handling equipment in the terminal [18,24]. Duin and Geerlings presented a methodology to calculate emissions of $\mathrm{CO}_{2}$ generated from the container terminal in the seaport [9]. The model was validated through different case studies (sea and inland container terminals) in the Netherlands. The model took into account the traveled distance and fuel consumption for each piece of equipment in the terminal but did not take congestion into account, which often takes place, and generates a significant amount of emissions. This model will be used in our study to calculate the emissions from both layouts of the container terminal with consideration of congestion and changing the layout of the terminal to improve the efficiency and decrease the emissions. 


\section{Common Container Terminal Layout}

Container terminals are described in some related references as an open system of cargo flow with two interface points (see Figure 1). The first interface point is the quayside, where the operations of loading and unloading the ships are done. The second interface point is the landside where the operations are of picking up containers by trucks and trains to move them to the next destination and vice versa [34]. Every terminal has a particular layout and associated dimensions between the different locations of operations in the terminal. The terminal's design determines these distances. Figure 1 illustrates the common layout of the container terminal. In the common container terminal layout, the location of the rail track and truck terminal is at the end of the terminal opposite the berth. This layout involves using different types of equipment to transfer containers from ship operations area to truck and train operations area. This equipment generates emissions in the terminal. Figure 1 demonstrates the sequence of operations in container terminals: After the container is brought to the terminal by train or truck, the container will be checked to identify and register it (e.g., destination, content, shipping lines, and exported ship). Internal equipment for transportation picks up the container and distributes it to its exact position in the yard (bay, row, and tier within the block) by using specific cranes. Finally, after the ship arrives, the container is discharged from its place in the storage yard block; it will then be carried to the quay where berth cranes pick up and load it onto the ship at the exact location, which is pre-defined based on the storage plan. The containers' import operations are executed in reverse order [35]. Improving container handling processes and making them more efficient will save energy and decrease emissions of $\mathrm{CO}_{2}$ [33]. The increase in the amount of container cargo results in a high level of demand for the services of container terminals at seaports, container logistics, and technical equipment [35].

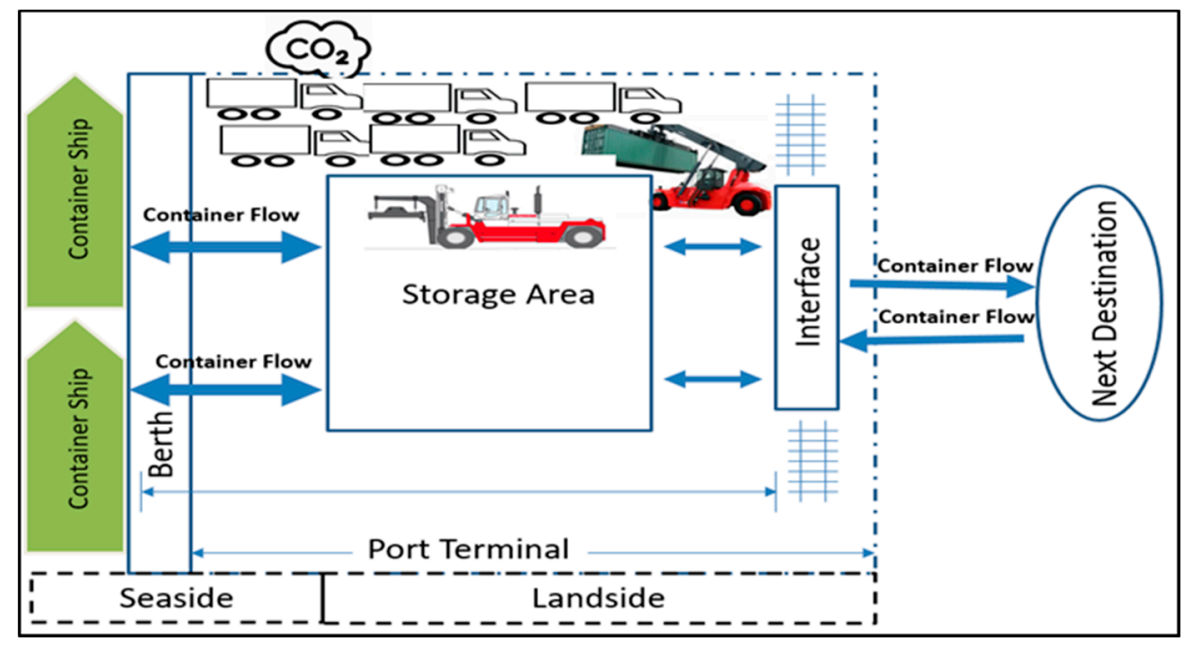

Figure 1. Common container terminal layout.

The environmental concern, aside from being assessed based on factors and measures that aim to decrease pollution, depends on the modal shift. In this situation, it is associated with economic factors because maritime transportation is becoming more attractive to transport cargo, and it is preferred to other kinds of transportation [36]. Scheduling several synchronized operations, activities with various modes of transportation, and handling equipment for containers are very complicated processes. Intermodal Transportation offers an opportunity to lower shipping costs and congestion. Shifting transportation systems from their route to rail and sea is a way to eliminate congestion on the roads, thus GHG emissions.

On the other hand, intermodal transportation systems in container terminals in ports face problems and challenges such as low efficiency, land scarcity, and labor shortage [2]. The result of solving such problems and overcoming the challenges will be an increase in terminal productivity and minimizing 
logistics of time, cost, and emissions (sustainability), thus increasing the capability of the container terminal to meet the recent high demand for containerization.

The literature review shows that prior studies have noticed the importance of the intermodal transportation system in reducing the cost and emissions. Although there are different researches in the field of container terminals and environmental effects of these operations, most of the studies that consider the environmental effects dealt with every mode of transportation individually. According to the literature review conducted by Lam et al., there is a big concern about a research gap in intermodal container flow with respect to sustainability [37]. Therefore, it is constructive for the analyses by taking into account sustainable intermodal transportation issues into the layout of the terminal with respect to environmental aspects, even though there is still a research gap in the field of sustainable intermodal transportation systems [27]. To the best of our knowledge, no study has been conducted and published on comparing different layouts of the container terminal in the seaport. In other words, there is an urgent need to focus upon the proposed novel terminal layout for the terminal efficiency. Whereby, this research aims to narrow the research gap and to develop a sustainable intermodal transportation system to enhance the efficiency of port activities, which is the main contribution of this paper. Besides, the comparison of time and cost between two layouts of the terminal, considering the congestion on the public roads, is an additional contribution. Moreover, evaluating the different combinations of import and export containers and testing the influence of these changes on the cost of transportation and travel time is being investigated.

\section{Case Study of Port of Montreal}

In order to examine the methodology's conduct and compare the results of the proposed layout and the Port of Montreal layout, a realistic case study was investigated. This investigation includes trucks, rail, and equipment that are used in the terminal as transportation and handling modes to transfer containers from the container ship to the destination and vice versa. We visited the site of Port of Montreal several times to observe the operations being conducted over there. We also collected the data from the respective authorities about its layout as well as its functioning. So, we took Port of Montreal, as our case study, and it has the same layout as the common layout, where the rail track is located at the end of the terminal. The location of the intermodal road terminal is also at the end of the terminal. The container terminal in the Port of Montreal uses trucks to transfer containers that have a domestic destination. The train is used to transport containers to destinations such as cities like Toronto, Detroit, and Chicago. However, the Port of Montreal has the problem of congestion due to:

a. At the peak period, truck traffic is increasingly congested because about 2500 trucks pass through the port daily. (According to the speech of Chief Executive of the Port Authority, 19 March 2015) [38].

b. Inefficient intermodal transportation causes congestions in the port, terminal, and area surrounding the port.

c. The distance between the berth and intermodal terminal and storage area causes an increase in the movement of trucks and equipment, thus increases the congestion from this equipment and trucks.

The congestion in the terminal generates GHG emissions in the atmosphere and, thus, air pollution in the port and surrounding area.

In order to formulate the problem, the sketch for the Montreal Port layout was created, shown in Figure 2. The layout of the current case study has three storage yards; firstly, storage yard for imported containers that have a domestic destination; secondly, a storage yard for exported containers; and lastly, storage yard for imported containers that transport to Toronto, Detroit, and Chicago. Each region represents a node. Arcs connect these nodes. Each arc presents transfer of a container from its origin to its destination by using a specific transportation mode. In addition to using road transportation to deliver containers that have domestic destinations, the train is used to deliver containers to different 
regions. Transportation by trucks is comparatively flexible regarding route and time of departure since there is no need to operate the trucks according to fixed schedules in the container terminal. Therefore, every container that arrives can be transported by truck. Travel time was calculated based on the distance between nodes and speed of transportation mode, considering congestion on the road.

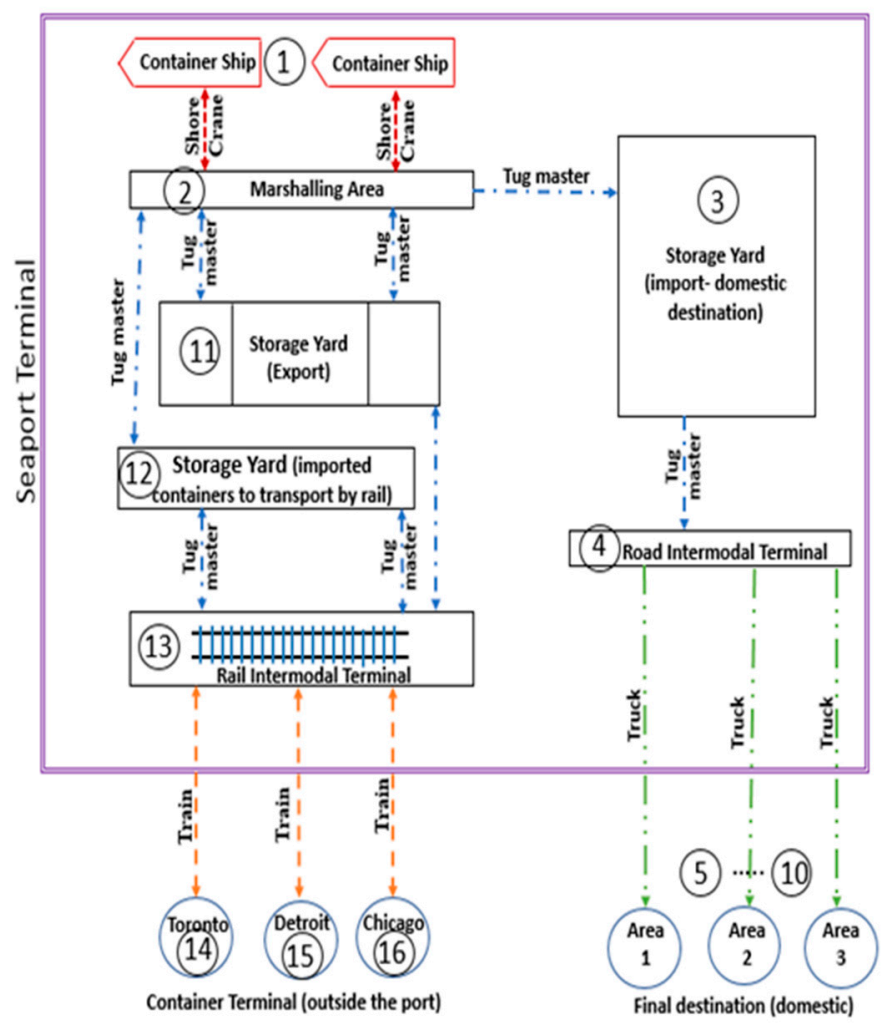

Figure 2. The layout of the Port of Montreal.

\section{Problem Definition}

Container terminals face many interconnected issues such as storage space allocation problems, crane assignment, truck assignment, and sustainable challenges [4]. In addition, nowadays, many ports face pressing regulatory and public policy pressures to work toward zero or near-zero emissions technology, which means electrification of most cargo handling equipment and other clean technologies for equipment that cannot run on electricity or batteries [39]. Many ports are not able to serve their customers with the right mix or standard of services because they do not have the right combination of infrastructure.

The long distance between the marshaling area and rail terminal influences the efficiency of the container terminals. It requires more horizontal transport vehicles to move containers between the marshaling area and rail terminal as well as cranes to lift the containers from the trucks and drop them on the real wagon or storage yard of a rail terminal and vice versa. Consequently, congestion will be higher. The amount of fuel consumption determines emissions, which is not the same for all sources of energy: for instance, the burning of a liter of diesel generates about $2.65 \mathrm{~kg}$ of $\mathrm{CO}_{2}$ [9]. Additionally, using trucks as multimodal transport may increase congestion at the terminal and impede terminal throughput. All of these factors influence terminal productivity and reduce container terminal efficiency.

Based on the problem definition, the research question is as follows:

How does the newly proposed sustainable intermodal terminal design layout improve port efficiency? 
To what extent does the new proposed layout contribute to the decrease in the cost of transportation handling and GHG emissions from the operations in the terminal?

Thus, the container terminal and movement of containers between the origins to their destination have become a source of concern for governments, environmental associations, and decision-makers. Therefore, studying and facing these challenges have become very necessary to guarantee container flow smoothly and minimize the negative impacts at the same time. So, we try to propose the novel approach by considering all the above concerns and propose the new layout, as seen in Figure 3.

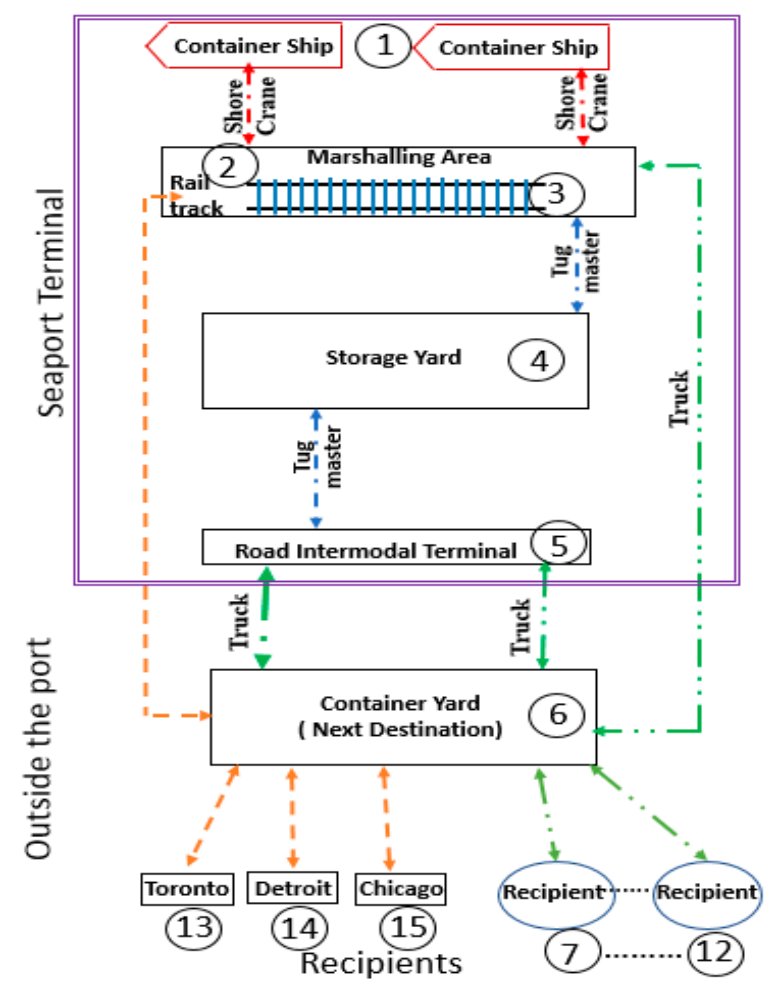

Figure 3. The proposed layout.

\section{Problem Formulation}

The Port of Montreal and the proposed layout of the terminal is divided into different locations, such as marshaling area, rail track, storage yard, etc., as shown in Figures 2 and 3. These locations are connected by arcs. The containers are transferred between these locations on the arcs by different modes of transportation. The different modes of transportation used in the terminal are as follows: Shore cranes are used to transfer containers between the ship and the seaside; tug master (diesel and electricity) is used to transfer containers between the nodes in the container's terminal in the seaport; trucks are used to carry containers from the intermodal road terminal in the seaport to the destination; and the train is used to transfer the containers from the intermodal rail terminal to the destination.

In this study, we propose another type of cargo equipment handling, which is an electric straddle carrier. Therefore, in order to minimize the cost and emissions at the same time, the model will tradeoff between the usage of electrical straddle carriers and diesel straddle carriers. In order to formulate the problem, a network representation of flows is designed for each layout. Figure 4 represents the network for the Port of Montreal layout, while Figure 5 represents a network for the proposed improved layout for the case of Port of Montreal. As we have seen in Figure 4 (the proposed layout), the nodes are rearranged for the optimization. Port of Montreal has three storage yards, whereas the proposed layout has only two storage yards, which is the difference between the two layouts. 


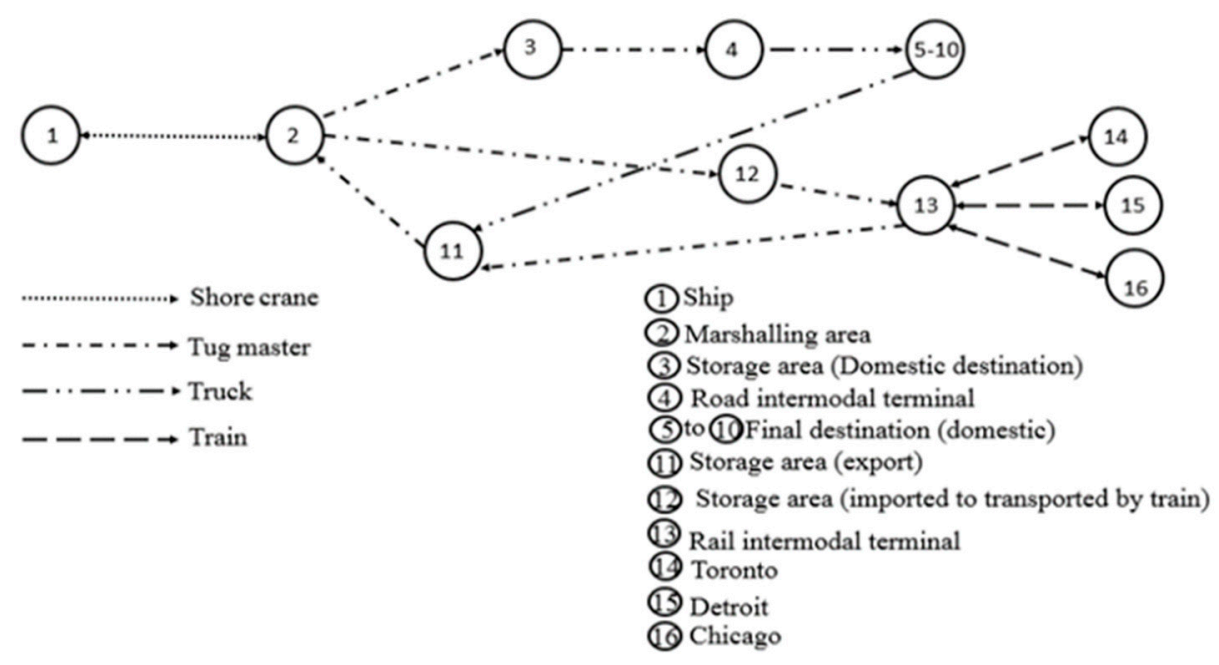

Figure 4. A network for the Port of Montreal layout.

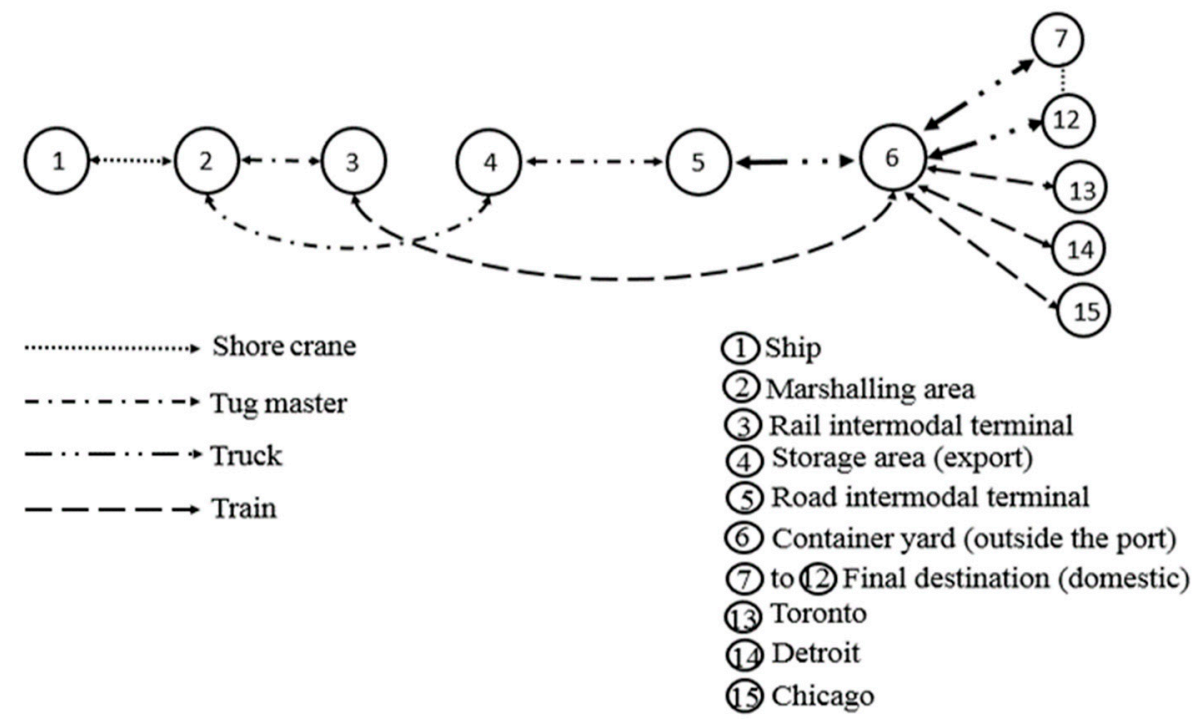

Figure 5. A network for the optimized proposed layout.

In this research, we solve the intermodal transportation system problem to minimize the cost and GHG emissions considering two objectives functions, considering the congestion on the arcs in the network. The objectives of the study are as follows:

The primary objective function aims to minimize the cost, while the second objective function is to minimize GHG emissions. The proposed model generates different Pareto-optimal solutions for activities of the intermodal transportation system in the Port of Montreal.

The framework of the problem's solution is illustrated in the flow chart Figure 6. Since the congestion function is a non-linear function, the approximation method will be used. The primary objective of approximation (Linearization) is to figure out the best representation of the original non-linear objective function of the model. A good expressing of piecewise linear functions has an effective role in minimizing the size of the problem and promoting the efficiency of computation. Generally, a piecewise linear function of a single variable $x$ with $m+1$ acts as a breakpoint by adding extra $m$ binary variables and $4 m$ constraints, which usually raise computational efforts when $\mathrm{m}$ becomes large. 


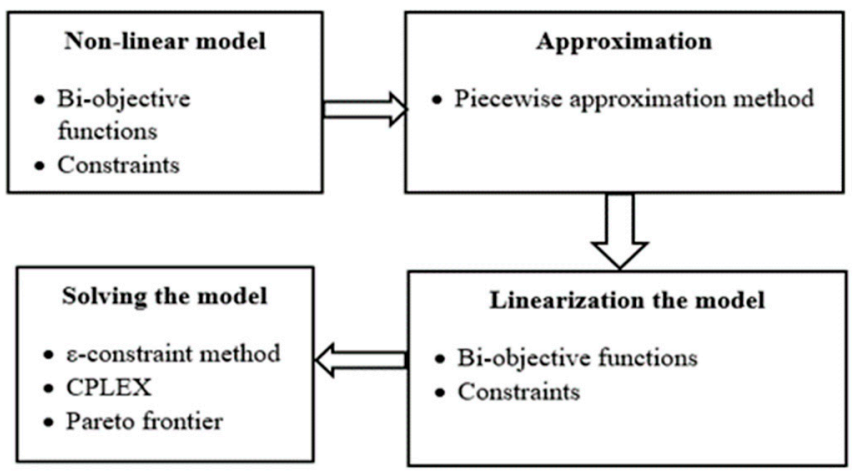

Figure 6. The framework of the problem solution.

$G=(N, A)$ is a network graph presenting the network of the container terminal and next container terminal, which is located outside the seaport. $N$ is a set of nodes, where every node $n \in N$ represents a specific element in the terminal. For example, a node could represent a ship, marshaling area, storage yard, intermodal road terminal, intermodal rail terminal, or container yard, which is the final distance in this modal.

On the other hand, $A$ is a set of arcs in graph $G$, where for every arc $a \in A$ and $(j, i, k) \in A$ and $a=(m, n, k)$ represents a link from node $\mathrm{m}$ to node $\mathrm{n}$ using transportation mode $k$, where $n, m \in N, a \in A$, and $k \in K$. The notations, scalars, parameters, and variables are as follows:

$K$ : Set of transportation modes.

$U$ : Set of container types.

$S_{n}^{+}$: Set of arcs that have origin node $n$.

$S_{n}^{-}$: Set of arcs that have destination node $n$.

Scalars

$\alpha$ : BPR (Bureau of Public Roads) equation constant.

$\beta$ : BPR (Bureau of Public Roads) equation exponent.

Parameters

$D_{n}^{u}$ : A number of containers type $u$ that already exist at node $\mathrm{n}$.

$P_{n}^{s}$ : The storage capacity of node $\mathrm{n}$.

$C_{u a}^{T}$ : Transportation cost per container of type $u$ on arc $a$.

$T_{a}^{u}$ : Transportation time of container type $u$ on an arc $a$.

$P_{k}^{t}$ : Total time available for transportation mode $k$.

$P_{u}^{s}$ : Unit storage space for container type $u$.

$H_{n}^{u}$ : Unit storage cost container type $u$ in node $n$.

$L_{a}$ : Length of $\operatorname{arc} a$.

$V_{k}$ : A speed limit of equipment types $k$ for free-flow transportation.

$v_{a}$ : The total volume of traffic on the arc.

$v_{e}$ : Speed of equipment on the port.

$\mathrm{Cap}_{a}$ : The overall capacity of the arc between node $\mathrm{i}$ and $\mathrm{j}$ for the mode of transportation $\mathrm{k}$.

$E_{u,(m, n, k)}^{T}$ : Total emission to transport container $u$ from node $m$ to node $n$ using equipment $k$.

$f_{k}$ : The factor of emission for electric equipment $=0.52$ (in $\mathrm{kg}$ of $\mathrm{CO}_{2}$ emission per $\mathrm{kWh}$ ), and $=$ 2.65 (in $\mathrm{kg}$ of $\mathrm{CO}_{2}$ emission per liter diesel).

$F_{k}$ : For fixed use, per ride in liters (such as lifting operations).

$r_{k}$ : Variable usage per $\mathrm{km}$ in liters.

$d$ : Traveled Distance for equipment $\mathrm{k}$. 
Variables

$y_{u n}$ : Number of containers type $u$ stored in node $n$.

$x_{u a}$ : Number of containers type $u$ moved on $\operatorname{arc} a$.

Objective functions:

$$
\begin{gathered}
\min f 1=\sum_{u \in U} \sum_{a \in A} C_{u,(m, n, k)}^{T} x_{u,(m, n, k)}+\sum_{u \in U} \sum_{n \in N} H_{n}^{u} y_{u n} \\
\min f 2=\sum_{u \in U} \sum_{a \in A} E_{u,(m, n, k)}^{T} x_{u,(m, n, k)} \\
T_{a}^{u}=\frac{L_{a}}{V_{e}} \\
T_{a}^{u}=\frac{L_{a}}{V_{k}} \times\left[1+\alpha\left[\frac{v_{a}}{C^{2} p_{a}}\right]^{\beta}\right] \\
E_{u,(m, n, k)}^{T}=f_{k}\left[F_{k}+r_{k} * d\right]
\end{gathered}
$$

Constraints

$$
\begin{gathered}
\sum_{a \in S_{n}^{-}} x_{u,(m, n, k)}-\sum_{a \in S_{n}^{+}} x_{u,(m, n, k)}=D_{n}^{u}+y_{u n} \forall n \in N, \forall u \in U \\
\sum_{u \in U} P_{u}^{s} y_{u n} \leq P_{n}^{s} \quad \forall n \in N \\
\sum_{a \in A} \sum_{u \in U} T_{(m, n, k)}^{u} x_{u,(m, n, k)} \leq P_{k}^{t} \quad \forall k \in K
\end{gathered}
$$

The functions (1) and (2) represent the objective functions. Function (1) is the cost objective function and function (2) is emissions function. The first expressing of Equation (1), expresses the total cost of transportation on the network while the second expressing indicates the overall cost of storage containers. In Equation (2), the first part shows the overall emissions corresponding to transfer containers from the container vessel to the last destination on the network. Since management of time functions a vital role in intermodal transportation problems, and it describes the main factor of the intermodal transportation cost. The cost of transportation equipment is determined based on the hourly cost of each type. Equation (3) is to calculate the traveling time of the equipment in the terminal, while the BPR equation (Equation (4)) is used to calculate the transportation congestion on the network because the BPR equation relies on the transported volume on the way [40]. Equation (5) is to calculate emissions from the container terminal. The model has three main constraint conditions. The first is the flow constraint; the second is the capacity of each node; and the last one is the capacity of the equipment. The rest of the constraints are to assure the non-negativity of the model variable. The Equation (6) is a set of constraints to enforce the maintenance of flow between the nodes. By Equation (7), we guarantee that the inventory capacity of the nodes that have a storage yard is not violated. The current layout has three storage yards: storage yard for an imported container which has a domestic destination, storage yard for imported containers which will be transported by train, and storage yard for exported containers. In contrast, the proposed layout has two storage yards: storage yard inside the port and container yard in a location outside the port. Equation(8) is a set of constraints to ensure that the time of using equipment $\mathrm{k}$ does not exceed the total time the company has available for equipment. The equation of BPR (Bureau of Public Records) [41] and, as seen in equation 4, was applied to calculate the congestion of traveling on the network. Equation (3) is used to figure out times of transportation of the modes considering the congestion on the road. In addition to road transportation, the times of transportation for equipment inside the seaport terminal and train modes are presumed to be fixed and calculated by using the average speed, Equation (2). The cost is calculated based on using the time 
of transportation mode. Based upon the case study, which represents the layout of Port of Montreal, we have described the problem definition, problem formulation, and the computational analysis in the following sections. The following sections will put an insight into the proposed layout, and the comparison has been made thereof.

\section{Approximation}

To introduce this method, let us consider a convex function $f(x)$ of a one-variable $x ; f(x)$ is a continued function, and $x$ is between the interval $\left[a_{0}, a_{m}\right]$ [42].

Firstly, denote $a_{k}(k=0,1, \ldots, m)$ as the breakpoints of $f(x), a_{0}<a_{1}<\ldots<a_{m}$, and Figure 7 presents the linearization of $f(x)$ using the piecewise method.

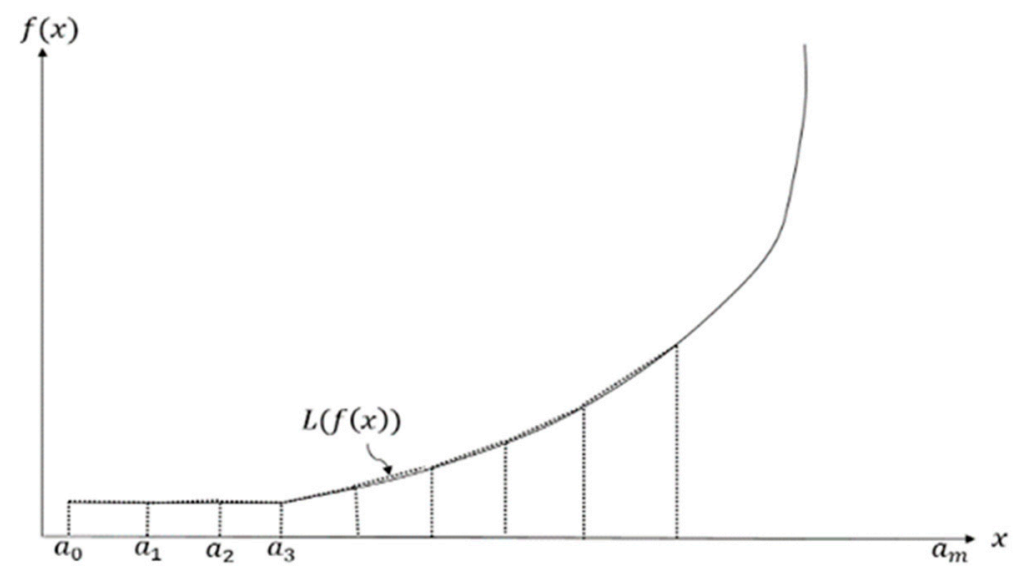

Figure 7. Piecewise linearization of $(x)$ (Adapted from [43]).

$f(x)$ then can be linearized approximately over the interval $\left[a_{0}, a_{m}\right]$ as:

$$
L(f(x))=\sum_{k=0}^{m} f\left(a_{k}\right) t_{k}
$$

where $x=\sum_{k=0}^{m} a_{k} t_{k}, \sum_{k=0}^{m} t_{k}=1, t_{k} \geq 0$, in which only two adjacent $t_{k}$ 's are liable to be nonzero. A nonlinear function is then changed into this equation.

$$
\begin{gathered}
L(f(x))=\sum_{k=1}^{m} f\left(a_{k}\right) t_{k} \\
x=\sum_{k=1}^{m} a_{k} t_{k} \\
\sum_{k=0}^{m} t_{k}=1
\end{gathered}
$$

This method is used to linearization the proposed model functions for both cost and emission as following:

$$
\min f 1=\sum_{u \in U} \sum_{a \in A} \sum_{b \in B} C_{u, a}^{T(b)} \hat{X} c_{u, a}^{b} t c_{u, a}^{b}+\sum_{u \in U} \sum_{n \in N} H_{n}^{u} y_{u n}
$$

where:

$$
\begin{gathered}
C_{u, a}^{T(b)}=G_{k(a)}^{b} W_{k(a)} T_{u, a} \\
\min f 2=\sum_{u \in U} \sum_{a \in A} \sum_{b \in B} E_{u, a}^{b} \hat{X} e_{u, a}^{b} t e_{u, a}^{b}
\end{gathered}
$$


where:

$$
E_{u, a}^{b}=f *\left(F_{k(a)}+G_{k(a)}^{b} r_{k(a)} d_{a}\right)
$$

subject to:

$$
\begin{gathered}
\sum_{a \in S_{n}^{-}} x_{u,(m, n, k)}-\sum_{a \in S_{n}^{+}} x_{u,(m, n, k)}=D_{n}^{u}+y_{u n} \\
\sum_{u \in U} P_{u}^{s} y_{u n} \leq P_{n}^{s} \quad \forall n \in N \\
\sum_{a \in A} \sum_{u \in U} T_{(m, n, k)}^{u} x_{u,(m, n, k)} \leq P_{k}^{t} \quad \forall k \in K \\
\sum_{u \in U} t c_{u, a}^{b}=1 \quad \forall u \in U, a \in A \\
\sum_{u \in U} t e_{u, a}^{b}=1 \quad \forall u \in U, a \in A \\
t c_{u, a}^{b}=t e_{u, a}^{b} \quad \forall u \in U, a \in A, b \in B \\
X_{u, a}=\sum_{u \in U} \hat{X} c_{u, a}^{b} t c_{u, a}^{b} \quad \forall u \in U, a \in A \\
X_{u, a}=\sum_{u \in U} \hat{X} e_{u, a}^{b} t e_{u, a}^{b} \forall u \in U, a \in A \\
t c_{u, a}^{b} \geq 0 \quad \forall u \in U, a \in A, b \in B \\
t e_{u, a}^{b} \geq 0 \quad \forall u \in U, a \in A, b \in B
\end{gathered}
$$

After approximation, the Equation (1) converted to Equation (9), which is a linear objective function of cost minimization. In a similar manner, Equation (2) turned into Equation (11) to represent the emission objective function. Additionally, for approximation, we introduce new terms, which are $\hat{X} c_{u, a}^{b}$ to denote to the number of breakpoints (b) on an arc $a$ in cost objective function. $\hat{X} e_{u, a}^{b}$ denotes to the number of breakpoints (b) on an arc $a$ in emission objective function, while $t c_{u, a}^{b}$ is a decision variable $\in\{0,1\}$ in cost objective function, and $t e_{u, a}^{b}$ is a decision variable $\in\{0,1\}$ in emission objective function. The Equation (10) is to calculate total cost based on time, taking into account congestion between nodes. Equation (12) is used to calculate the emission from every piece of equipment. Constraints (6)-(8) have been previously explained. Constraints (13), (14), (18) and (19) are devoted to maintaining the values of $t c_{u, a}^{b}$ and $t e_{u, a}^{b}$ within $\{0,1\}$. Equation (15) is linking constraint, to link decision variable $t c_{u, a}^{b}$ in cost objective function with $t c_{u, a}^{b}$ in emission objective function. Constraints (16) and (17) to link $X_{u, a}$ with $\hat{X} c_{u, a}^{b} t c_{u, a}^{b}$ and $\hat{X} e_{u, a}^{b} t e_{u, a}^{b}$ in cost objective function and emission objective function, respectively based on the piecewise linearization method.

The epsilon constraint method is applied to find a solution to this problem [43]. The epsilon constraint method generates non-extreme efficient solutions, and usually, each run generates a different and new efficient solution, so a number of these solutions are beneficial for decision-makers. After calculating the lower and upper bounds of the function of the cost and the emission function, respectively, the epsilon constraint method is applied.

\section{Computational Results}

The data used in this model include distances between the nodes in the network, transportation modes, fuel consumption, transfer costs and times, average speeds for transportation modes and equipment that are used in handling and transferring containers, and costs of storage containers in the seaport. This data involves the Port of Montreal as a real case study. There are some restrictions 
on using transportation modes on the network because every mode of transportation is designed for performing a different task. The data was collected based on the operations in the Port of Montreal.

The collecting data started from March 2017 until October 2017. The Port of Montreal layout and its dimensions were drawn based on real layout through many visits to the Port of Montreal and meetings with the Operations Manager. The measurement of distances were taken between the nodes from the map of the port and measured by Google Earth. The number of equipment is the real number used by the Port of Montreal. Speed and time of movement of the equipment were taken from the manufacturer's manual. In the computational results, we presented an overview of both layouts and related data used in this model and computed the analysis of the results obtained. The model of this study was written in the IBM ILOG OPL Studio modeling environment. However, the model was solved by using IBM ILOG CPLEX 12.1 [44]. The model is executed on a computer with $2.50 \mathrm{GHz}$ dual-core processor, with Intel Core I5 2520M CPU, and with $4.00 \mathrm{~GB}$ of RAM. The mathematical model showed in this paper is applied to the Port of Montreal with a network containing five different transportation modes (shore crane, diesel tug master, electrical tug master, road, and rail). Using transportation modes between the nodes differs based on the characteristic of each mode of transportation and type of operation. Figures 2 and 3 show feasible links between the nodes for varying modes of transportation in the current and proposed layout, respectively. The layout of the container terminal of Montreal Port shows that the location of the rail track and truck terminal is at the end of the terminal, as shown in Figure 2, and this is the common layout in many terminals. In this section, we will solve both Port of Montreal and proposed layout as a bi-objective function problem to minimize the cost function, and GHG emissions function simultaneously. We will also present a comparison between them. In order to use the $\varepsilon$-constraint method for both layouts, the emission function was minimized to find the bounds of the objective function. Then, this value was used as a constraint in addition to constraints, Equations (13)-(22) to minimize the cost function. The right-hand-side value of the emission function changes in each iteration of the $\varepsilon$-constraint method by adding the $\varepsilon$ value for the iteration to the lower bound of the emission function. The solution depends on the decision-makers' preferences, if the emission has higher priority, they will choose the solution with low emission and high cost, or they can tradeoff between the number of emissions and the cost to find an acceptable solution which meets minimization of emissions and cost. In order to derive the solution, we had used the $\varepsilon$-constraint method for the Multi-objective problem, which thereafter generate the Pareto set with varying solutions. So, the problem is reformulated by keeping the cost function as an objective function and transforming the emission function to a constraint. Eventually, the implementation of the $\varepsilon$-constraint for both layouts becomes as follows:

$$
\min f 1=\sum_{u \in U} \sum_{a \in A} \sum_{b \in B} C_{u, a}^{T(b)} \hat{X} c_{u, a}^{b} t c_{u, a}^{b}+\sum_{u \in U} \sum_{n \in N} H_{n}^{u} y_{u n}
$$

subjected to:

$$
\sum_{u \in U} \sum_{a \in A} \sum_{b \in B} E_{u, a}^{b} \hat{X} e_{u, a}^{b} t e_{u, a}^{b} \leq \varepsilon
$$

and the rest of the constraints can be seen in (Equations (6)-(8) and (13)-(19)).

To develop the Pareto set of the Port of Montreal and the proposed layout, we determined the optimal value of the emission function ( $f 2)$ only. Afterward, we considered the obtained value of $f 2$ as the epsilon value of optimized cost function $(f 1)$. The value of epsilon has been changed multiple times within the imposed range of the upper and lower bounds. Before delving into the Pareto sets, we show the difference between the Cost of Transportation comparisons between Port of Montreal and the proposed layout, which can be seen in Figures 8 and 9, considering cost and emissions, respectively. 


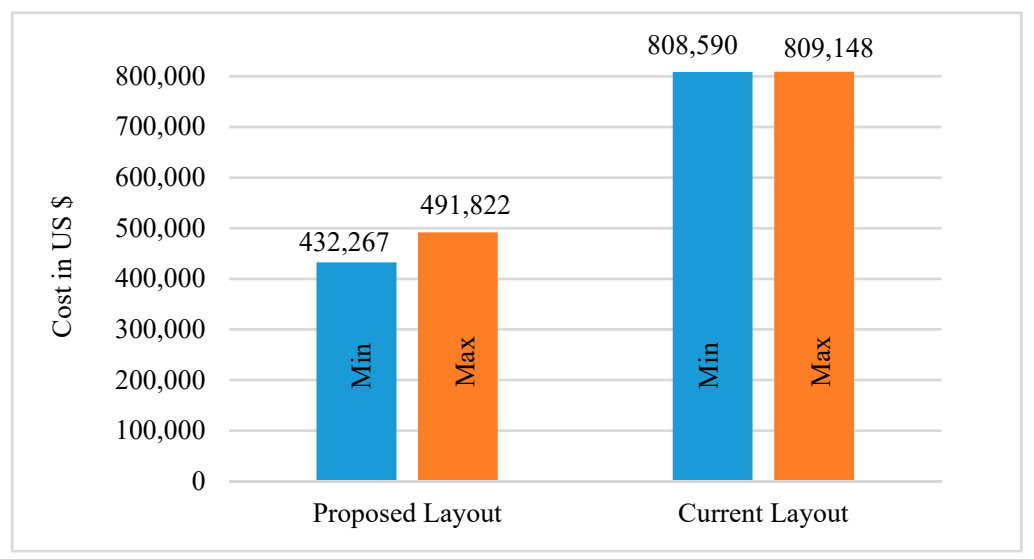

Figure 8. Cost of transportation comparison.

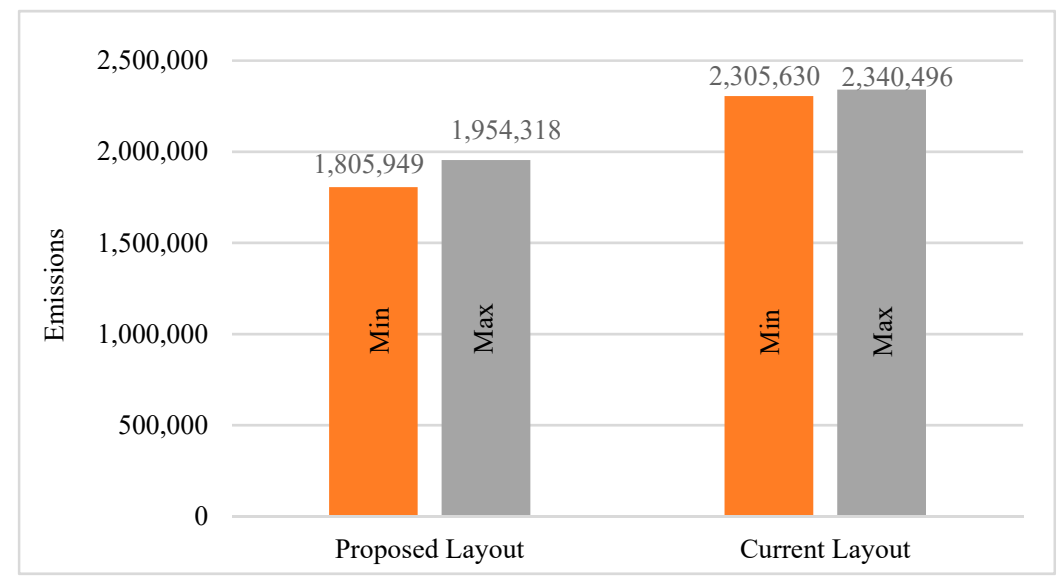

Figure 9. Emissions comparison.

From Figure 8, the proposed layout proposal demonstrated a notable reduction in the overall cost by $46.5 \%$ compared to the Port of Montreal layout, while the minimum emissions decreased by $21.6 \%$. Figure 9 shows a comparison of the minimum and maximum values of emissions between both layouts. In addition, the flow of containers became smoother, where the congestion was minimized.

The main reason behind taking into account the congestion is to reduce emissions and to save the time of transportation of containers from the origin node to the destination, whereby, reducing the cost. The results show the cost of container transportation from the berthed ship to the final destinations. It also shows that the time of the proposed layout is less than the cost and time of transportation of the common layout; Table 1 shows this comparison.

Table 1. Cost and emissions comparison between the layouts.

\begin{tabular}{ccc}
\hline & Current Layout & Proposed Layout \\
\hline Minimum total cost (in thousands) & $\$ 808,590$ & $\$ 432,267$ \\
Minimum total emission (kg CO2e) & $2,305,630$ & $1,805,949$ \\
Difference \% in the total cost $46.5 \%$ & \\
Difference $\%$ in the total emission $21.6 \%$ & \\
\hline
\end{tabular}

It is clear that the proposed layout produces a significantly lower level of $\mathrm{CO}_{2}$. This can be explained while the proposed layout relatively decreased the amount of equipment used in handling and transferring the containers, and in addition, traveled distances.

By using the objective function as discussed above, we had generated the Pareto sets of Port of Montreal and Proposed Layout. The Port of Montreal layout Pareto set, which is represented 
in Figure 10, shows the minimum cost $\$ 808,589.80$ with emission 2,340,496 $\mathrm{kg} \mathrm{CO} 2 \mathrm{e}$, whereas the proposed layout, as represented in Figure 11, shows the minimum cost $\$ 432,266.60$ with emission $1,954,317.7 \mathrm{~kg}$ CO2e. By this, we can clearly see, we had significantly optimized cost and emission by using the proposed layout.

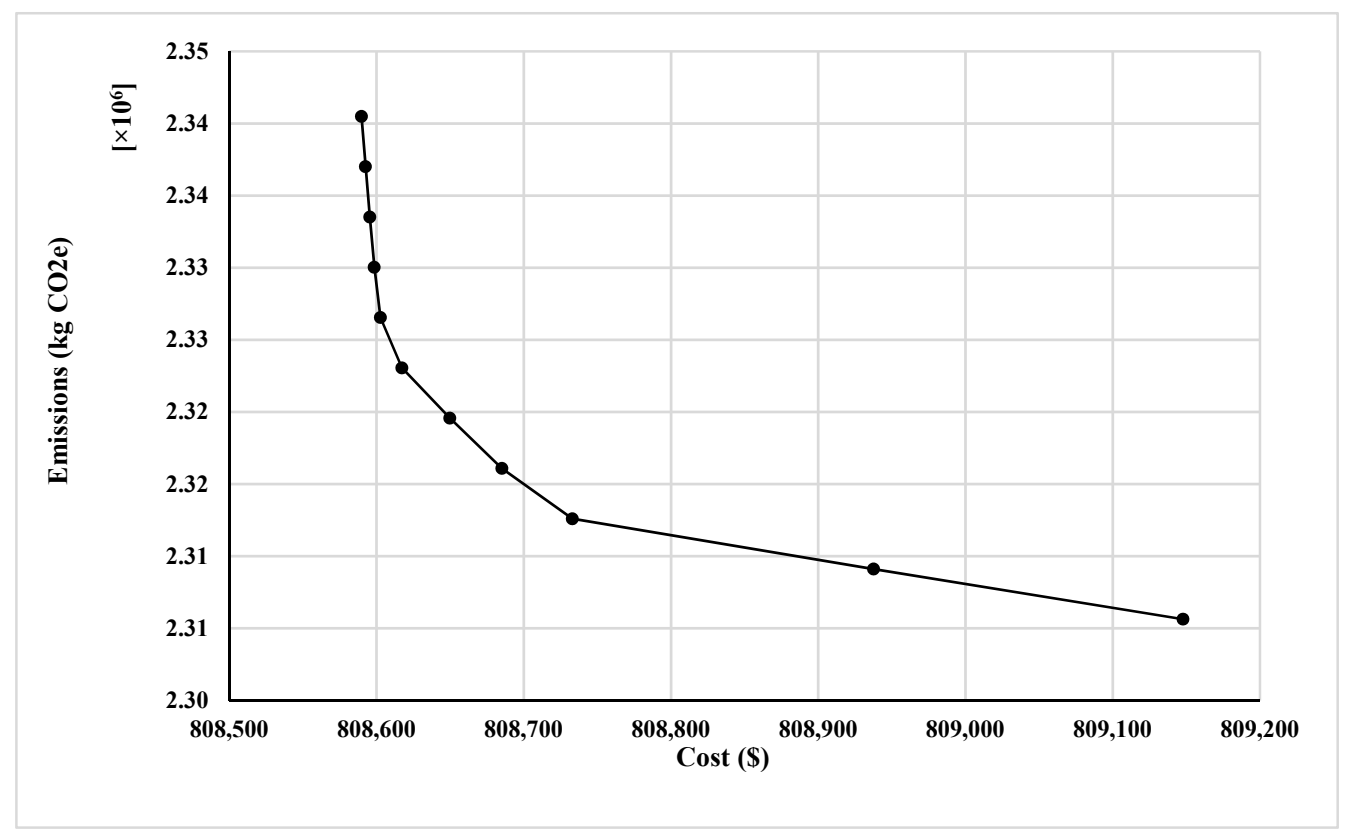

Figure 10. Pareto solutions of the Port of Montreal layout.

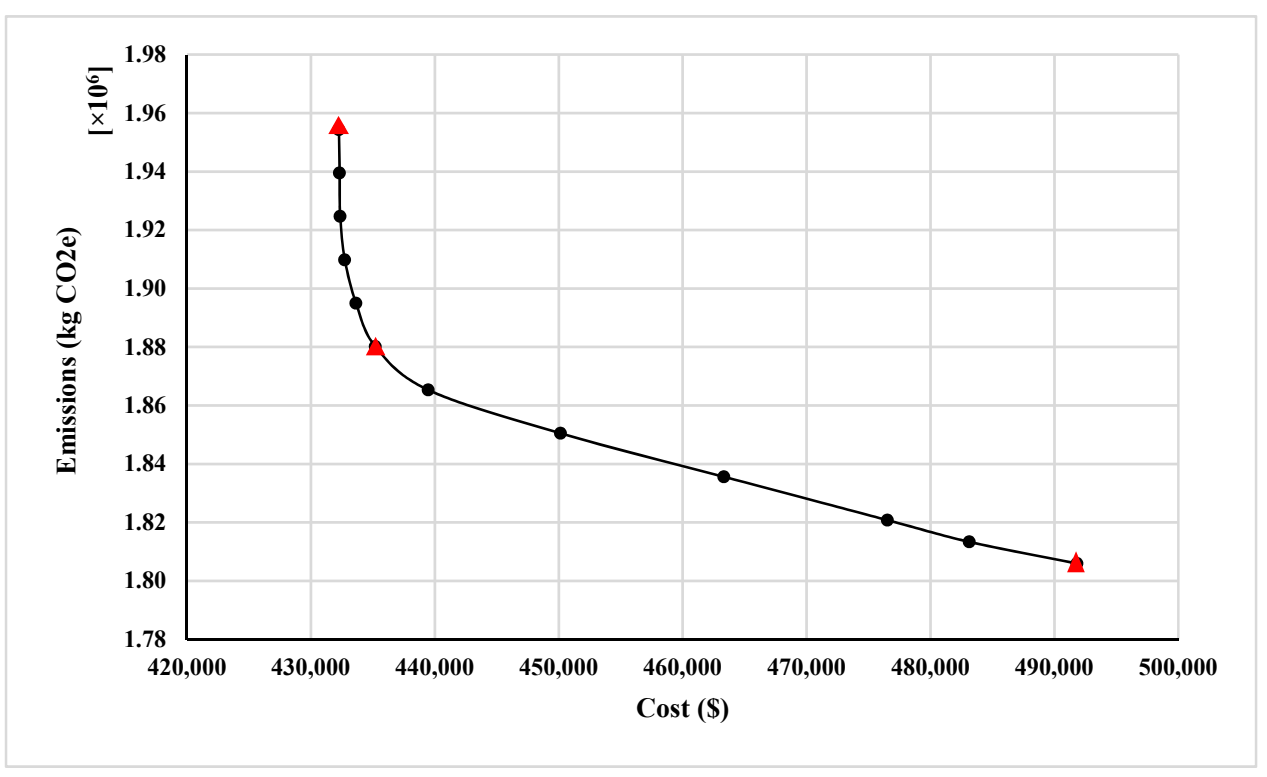

Figure 11. Pareto solutions of the proposed layout.

Now, taking into consideration Figure 11 (Proposed Layout Pareto set), we had selected three different solutions from Figure 11, which represent the minimum, average, and maximum values of the solution. These solutions are indicated on the graph with a red triangle. These solutions were analyzed in Table 2. 
Table 2. Cost-emissions comparison of different solutions in the proposed layout.

\begin{tabular}{cccc}
\hline & Solution I & Solution II & Solution III \\
\hline Total cost (\$) & $491,821.60$ & $439,481.15$ & $432,266.6$ \\
Total emissions (kg CO2e) & $1,805,949.47$ & $1,865,296.762$ & $1,954,317.70$ \\
\hline & Solutions I and II & \multicolumn{2}{c}{ Solutions II and III } \\
\hline Difference \% in the total cost & 11.9 & \multicolumn{2}{c}{1.67} \\
Difference \% in the total emissions & 3.3 & 4.8 \\
\hline
\end{tabular}

According to the analysis in Table 2, while minimizing the cost factor by $11.9 \%$, only $3.3 \%$ of additional emissions are incurred on the overall emissions. Furthermore, if the total cost decreases by $1.67 \%$, only $4.8 \%$ of extra emissions must be emitted to fulfill that requirement. Since the objective of the proposed layout is minimizing the total cost of transportation containers as well as the number of equipment and trucks used in transferring containers, the optimal solution depends on the preferences of decision-makers. These outcomes may provide strategic management with a valuable guide to reduce the negative impact of the port operations. Based on the results, mitigating the negative impacts of port operations on the environment requires moving the focus of decision-makers from financial and operational performance to environmental performances. The port infrastructure should be adopted and upgraded to achieve this goal. These include changing the layout of the terminal and shifting from road transportation to rail tracks, establishing a remote container terminal outside the city, and connecting it with the port depending on rail tracks more than trucks. Moreover, using electric equipment in container handling is a way to lower emissions. This paper analyzes and evaluates the performance of the current terminal layout and the proposed layout in terms of cost, time, and environment. The proposed layout considers all the factors that help in reducing emissions. These factors include using electric equipment, establishing a remote container terminal, and connecting this terminal with the port by rail tracks. However, most ports in the world are surrounded by cities, and they are not able to extend their borders. Thus, the proposed layout takes this issue into account, and it works with a remote container terminal. In the proposed layout, most of the containers will move to the remote container terminal, and the container yard in the port will keep the containers that have a domestic destination. Therefore, there is no need for a spacious storage yard in the port.

\section{Conclusions}

Although problems of container terminals in the ports have been well studied from engineering, economic, and management aspects, numerous significant issues have yet to get the attention that they deserve. Enhancing terminal operations' efficiency is pivotal to improve maritime shipping reliable, which we had done over here by proposing the novel layout. The Port of Montreal Layout has several deficiencies due to the flow trade changes, and can be improved by implementing our proposed layout. The major contribution of the paper is proposing the novel model, which reduces, simultaneously, the cost and emissions in the environment. Hence, we tried to find a sustainable layout for decreasing the ever-increasing emissions from the port industry. Yet, further study can be done for the expense of the implementation of the proposed layout. In this paper, the optimization of the intermodal transportation problem is also studied for different modes of transportation in order to minimize the cost and emissions principle by considering traffic congestion. The results of this research reveal significant managerial insights, such as the advantages of reducing the distance between the berth and rail intermodal terminal and introducing another container yard out of the city. Moreover, there is a dependence on rail transportation to move the containers from the port to the container yard. The study will help decision-makers in the seaports industry to evaluate investment decisions in container terminals. In addition, the study could be used by port authorities in evaluating port performance. Moreover, the results of this study will help to obtain more effective solutions for intermodal transportation to create more balance between the conflicting objectives: emissions and 
costs. The study will help to maximize the benefits of the intermodal transportation system, such as environmental advantages. The implementation of the proposed layout will lead to effective use of the land, which is usually limited and impossible to expand because the ports usually are surrounded by the city. Implementation of this proposed layout depends on the port infrastructure and the accurate configuration between the ship and train regarding the handling operations. Future work in the intermodal transportation system area is using simulation to evaluate the performance of different layouts in the terminal. In addition, researches on how to choose geographical locations for inland intermodal terminals is required.

Author Contributions: T.A.A. is the main author and he proposed the idea of the paper, which was reviewed and approved by professors M.O. and M.P. The full manuscript written by the main author and intensively reviewed by the other authors. All authors have read and agreed to the published version of the manuscript.

Funding: This research received no external funding.

Acknowledgments: The main author acknowledges Mustapha and Marc for their valuable comments on this work. Additionally, we are grateful to the reviewers for a careful and thorough reading of this manuscript which improved this work.

Conflicts of Interest: The authors declare no conflict of interest.

\section{References}

1. Lin, C.-C.; Lin, S.-W. Two-stage approach to the intermodal terminal location problem. Comput. Oper. Res. 2016, 67, 113-119. [CrossRef]

2. Lee, C.-Y. Handbook of Ocean Container Transport Logistic: Making Global Supply Chains Effective; Springer: New York, NY, USA, 2015.

3. Qu, Y.; Bektaş, T.; Bennell, J.A. Sustainability SI: Multimode Multicommodity Network Design Model for Intermodal Freight Transportation with Transfer and Emission Costs. Netw. Spat. Econ. 2014, 16, 303-329. [CrossRef]

4. Othman, M.R.; Jeevan, J.; Rizal, S. The Malaysian Intermodal Terminal System: The Implication on the Malaysian Maritime Cluster. Int. J. e-Navig. Marit. Econ. 2016, 4, 46-61. [CrossRef]

5. Demir, E.; Burgholzer, W.; Hrušovský, M.; Arikan, E.; Jammernegg, W.; Van Woensel, T. A green intermodal service network design problem with travel time uncertainty. Transp. Res. Part B Methodol. 2016, 93, 789-807. [CrossRef]

6. IEA. $\mathrm{CO}_{2}$ Emissions Statistics. 2019. Available online: https://www.iea.org/statistics/co2emissions/ (accessed on 5 February 2020).

7. Hossain, T.; Adams, M.; Walker, T.R. Sustainability initiatives in Canadian ports. Mar. Policy 2019, 106, 103519. [CrossRef]

8. Environment and Climate Change Canada. Canadian Environmental Sustainability Indicators: Greenhouse Gas Emissions. Available online: https://www.canada.ca/content/dam/eccc/documents/pdf/cesindicators/ ghg-emissions/2019/national-GHG-emissions-en.pdf (accessed on 6 February 2020).

9. Van Duin, J.H.R.; Geerlings, H. Estimating $\mathrm{CO}_{2}$ footprints of container terminal port-operations. Int. J. Sustain. Dev. Plan. 2011, 6, 459-473. [CrossRef]

10. ElSayed, L.A.-M. An Agent-based Approach for Improving the Performance of Distributed Business Processes in Maritime Port Community; University of Plymouth: Plymouth, UK, 2012.

11. Chopra, S.; Meindl, P. Supply Chain Management: Strategy, Planning and Operation, 5th ed.; Pearson Education: London, UK, 2013.

12. Urbanyi-Popiołek, I.; Klopott, M. Container Terminals and Port City Interface-A Study of Gdynia and Gdańsk Ports. Transp. Res. Procedia 2016, 16, 517-526. [CrossRef]

13. Wang, H. A Study of System Performance Measures for Intermodal Transportation; Mississippi State University: Starkville, MS, USA, 2004.

14. Mostert, M.; Caris, A.; Limbourg, S. Intermodal network design: A three-mode bi-objective model applied to the case of Belgium. Flex. Serv. Manuf. J. 2017, 30, 397-420. [CrossRef]

15. Hanssen, T.-E.S.; Mathisen, T.A.; Jørgensen, F. Generalized Transport Costs in Intermodal Freight Transport. Procedia Soc. Behav. Sci. 2012, 54, 189-200. [CrossRef] 
16. Bektas, T.; Crainic, T.G. Brief Overview of Intermodal Transportation. Cirrelt 2007. [CrossRef]

17. López-Navarro, M. Environmental Factors and Intermodal Freight Transportation: Analysis of the Decision Bases in the Case of Spanish Motorways of the Sea. Sustainability 2014, 6, 1544-1566. [CrossRef]

18. Chen, G.; Govindan, K.; Golias, M.M. Reducing truck emissions at container terminals in a low carbon economy: Proposal of a queueing-based bi-objective model for optimizing truck arrival pattern. Transp. Res. Part E Logist. Transp. Rev. 2013, 55, 3-22. [CrossRef]

19. European Commission. Roadmap to A Single European Transport Area-Towards A Competitive and Resource Efficient Transport System. White Paper; European Commission: Brussels, Belgium, 2011.

20. Aditjandra, P.T.; Zunder, T.H.; Md Zahurul Islam, D.; Palacin, R. Green Rail Transportation: Improving Rail Freight to Support Green Corridors; Springer: Berlin, Germany, 2016.

21. Woodburn, A. Effects of rail network enhancement on port hinterland container activity: A United Kingdom case study. J. Transp. Geogr. 2013, 33, 162-169. [CrossRef]

22. Bichou, K. An empirical study of the impacts of operating and market conditions on container-port efficiency and benchmarking. Res. Transp. Econ. 2013, 42, 28-37. [CrossRef]

23. Kozan, E. Optimum Capacity for Intermodal Container Terminals. Transp. Plan. Technol. 2006, $29,471-482$. [CrossRef]

24. Geerlings, H.; van Duin, R. A new method for assessing $\mathrm{CO}_{2}$-emissions from container terminals: A promising approach applied in Rotterdam. J. Clean. Prod. 2011, 19, 657-666. [CrossRef]

25. Chen, J.; Huang, T.; Xie, X.; Lee, P.T.-W.; Hua, C. Constructing Governance Framework of a Green and Smart Port. J. Mar. Sci. Eng. 2019, 7, 83. [CrossRef]

26. Gibbs, D.; Rigot-Muller, P.; Mangan, J.; Lalwani, C. The role of sea ports in end-to-end maritime transport chain emissions. Energy Policy 2014, 64, 337-348. [CrossRef]

27. Sim, J. A carbon emission evaluation model for a container terminal. J. Clean. Prod. 2018, 186, 526-533. [CrossRef]

28. Liu, D.; Ge, Y.-E. Modeling assignment of quay cranes using queueing theory for minimizing $\mathrm{CO}_{2}$ emission at a container terminal. Transp. Res. Part D Transp. Environ. 2018, 61, 140-151. [CrossRef]

29. Liu, H.; Wang, F.; Zhang, Z. Application of electricity instead of oil technology to RTGs for port energy conservation and pollution reduction. Port Waterw. Eng. 2011, 9, 123-125.

30. Yu, H.; Ge, Y.-E.; Chen, J.; Luo, L.; Tan, C.; Liu, D. CO $\mathrm{CO}_{2}$ emission evaluation of yard tractors during loading at container terminals. Transp. Res. Part D Transp. Environ. 2017, 53, 17-36. [CrossRef]

31. Berechman, J.; Tseng, P.-H. Estimating the environmental costs of port related emissions: The case of Kaohsiung. Transp. Res. Part D Transp. Environ. 2012, 17, 35-38. [CrossRef]

32. Hirvonen, A.; Salonen, H.; Söderberg, P. Reducing Air Emissions in a Container Terminal; Overview of Means Related to Cargo Handling Equipment. Available online: https://www.kalmarglobal.com/48e087/globalassets/ newsroom/kalmar_whitepaper_reducing-air-emissions-in-a-container-terminal_web.pdf (accessed on 5 February 2020).

33. Demir, E.; Bektaş, T.; Laporte, G. A comparative analysis of several vehicle emission models for road freight transportation. Transp. Res. Part D Transp. Environ. 2011, 16, 347-357. [CrossRef]

34. Stahlbock, R.; Voss, S. Operations Research at Container Terminals: A Literature Update; Springer: Berlin, Germany, 2007.

35. Voß, S.; Stahlbock, R.; Steenken, D. Container terminal operation and operations research-A classification and literature review. OR Spectr. 2004, 26, 3-49. [CrossRef]

36. PWC; Panteia. Measures to Enhance the Efficiency and Quality of Port Services on the EU. Available online: https://safety4sea.com/measures-to-enhance-the-efficiency-and-quality-of-port-services-on-the-eu/ (accessed on 5 February 2020).

37. Lam, J.S.L.; Gu, Y. Port hinterland intermodal container flow optimisation with green concerns: A literature review and research agenda. Int. J. Shipp. Transp. Logist. 2013, 5, 257-281. [CrossRef]

38. Port of Montreal. Presentations and Speeches 2015. Available online: https://www.port-montreal.com/en/ presentations-and-speeches-community.html (accessed on 6 February 2020).

39. Mongelluzzo, B. Path to Slashing Zero-Emissions Costs to California Ports Proposed. Available online: https://www.joc.com/port-news/us-ports/port-los-angeles/path-slashing-zero-emissions-costscalifornia-ports-proposed_20170803.html (accessed on 5 February 2020). 
40. BPR. Traffic Assignment Manual: Bureau of Public Roads; U.S. Department of Commerce: Washington, DC, USA, 1964.

41. Maerivoet, S.; De Moor, B.L.R. Transportation Planning and Traffic Flow Models. Available online: https://arxiv.org/abs/physics/0507127 (accessed on 5 February 2020).

42. Lin, M.-H.; Carlsson, J.G.; Ge, D.; Shi, J.; Tsai, J.-F. A Review of Piecewise Linearization Methods. Math. Probl. Eng. 2013, 2013, 1-8. [CrossRef]

43. Mavrotas, G. Effective implementation of the $\varepsilon$-constraint method in Multi-Objective Mathematical Programming problems. Appl. Math. Comput. 2009, 213, 455-465. [CrossRef]

44. IBM. IBM ILOG CPLEX Optimization Studio. Available online: https://www.ibm.com/ca-en/products/ilogcplex-optimization-studio (accessed on 6 February 2020).

(C) 2020 by the authors. Licensee MDPI, Basel, Switzerland. This article is an open access article distributed under the terms and conditions of the Creative Commons Attribution (CC BY) license (http://creativecommons.org/licenses/by/4.0/). 